\title{
Effect of medial bulboreticular and raphe nuclear lesions on the excitation and modulation of supraspinal nocifensive behaviors in the cat
}

\author{
Kenneth L. Casey ${ }^{1,2,3}$ and Thomas J. Morrow ${ }^{2,3}$ \\ Departments of ${ }^{1}$ Neurology and ${ }^{2}$ Physiology and the ${ }^{3}$ Neurology Research Laboratories, University of Michigan, VA Medical \\ Center, Ann Arbor, MI 48105 (U.S.A.)
}

(Accepted 4 April 1989)

Key words: Analgesia; Nociception; Pain; Temperature; Behavior

\begin{abstract}
Six cats were trained to eat while partially restrained and while thermal pulse stimuli $\left(43-60^{\circ} \mathrm{C}, 5 \mathrm{~s}\right.$ duration) were delivered to the upper hindlimbs. Food and stimulus delivery were under programmed electronic control. The probability and latency of 3 natural, unlearned nocifensive behaviors were electronically registered: interruption of eating or of exploring for food, hindlimb movement and vocalization. Preoperatively, all cats showed significant increases in the probability of two or more behaviors as stimulus temperature increased. Each cat also showed a significant food-induced suppression of one or more of these behaviors. Thermocoagulation lesions limited to the giganto- and magnocellular fields of the medial medullary reticular formation (4 cats) produced a decrease in nocifensive responsiveness. Larger lesions within the same area but with extension into the postpyramidal raphe nuclei, resulted in increased nocifensive responsiveness ( 2 cats). No lesion affected response latency or the food-induced modulation of nocifensive behavior. The results support the hypothesis that supraspinally organized nocifensive responses are: (1) tonically facilitated by neural activity originating in or passing through the medial bulboreticular formation; (2) tonically suppressed by midline raphe spinal neurons; and (3) phasically modulated by suprabulbar neural mechanisms that are related to changes in behavioral state.
\end{abstract}

\section{INTRODUCTION}

During the past decade, numerous experiments have added detail to our understanding of the neural mechanisms by which the brainstem could mediate and modulate behavioral responses to noxious somatic or visceral stimuli ${ }^{7,26,27,29,39,55,66}$. The emerging picture is one of separate, juxtaposed groups of brainstem neurons with rostrally or caudally projecting axons and with the potential to facilitate or suppress nociceptive neuronal transmission and nocifensive behavioral responses. With few exceptions, however, (cited in Discussion) there are no experiments that demonstrate the predominant effect, on supraspinally organized nocifensive behavior, of destroying or otherwise inactivating different brainstem regions. Experiments of this type are necessary if we are to learn about the functional significance of putative pain-modulating neurons.

We have developed a method for measuring supraspinally organized, unlearned, nocifensive responses of cats to controlled thermal stimuli so that changes in stimulus-response profiles can be determined ${ }^{17}$. This method has been used to demonstrate the effect of spinal tractotomies on the tonic excitability and phasic modulation of nocifensive behavior ${ }^{18}$. In this report, we present the results of similar experiments in which stimulus-response profiles of cats, and the natural, environmentally induced modulation of these profiles, were determined before and after placing thermocoagulation lesions in the medial medulla. Preliminary reports of these experiments have been published ${ }^{19}$.

Correspondence: K.L. Casey, Chief, Neurology Service (127). VA Medical Center, 2215 Fuller Road, Ann Arbor, MI 48105, U.S.A. 


\section{MATERIALS AND METHODS}

All animals in this study were maintained in facilities that were fully accredited by the American Association for Accreditation of Laboratory Animal Care. We used the minimum number of animals necessary to obtain reliable results.

\section{Testing of responses to thermal stimuli}

The procedure is the same as previously described ${ }^{18}$ but will be summarized briefly. Six normal adult female cats were trained to place their muzzles into an illuminated food cup, thereby interrupting a photocell contact and triggering the delivery of three 1.5-ml portions of pureed meat-based cat foot during a 15-s period. After 1-2 weeks of preliminary conditioning, the cats were trained for another 2 weeks to perform the same task while partially restrained in a flexible body cast. Cats were food deprived for $24 \mathrm{~h}$ before training or data collection sessions 5 days per week.

Thermal pulses were delivered to either shaved outer thigh by spring-loaded, water-cooled contact thermodes ${ }^{48}$. Glycerine was applied to the skinthermode interface to assist heat transfer and an electric razor was used to shave the skin twice weekly. Stimuli rose from an adapting temperature of $38^{\circ} \mathrm{C}$ at a rate of $17^{\circ} \mathrm{C} / \mathrm{s}$. Unless terminated by the cat's response, thermal pulses had a plateau duration of $5 \mathrm{~s}$ and returned to the adapting temperature within $2 \mathrm{~s}$.

Three behavioral responses were recorded only during the 7-s-stimulus period. Vocalization was detected by microphone, movement of the body by a weighted phonograph cartridge mounted between the hindlimb supports, and interruption of eating or of exploration for food by activation of a photocell mounted in the illuminated food cup. The amplified output of each of these devices was led into separate level-detection comparator circuits, each with an output that could be selected to terminate the stimulus. Movement responses sufficient to trigger the detector produced just-visible displacements of the cast and registered $300-\mathrm{g}$ peaks on a force transducer mounted on the cast wall. The movement sensor could be activated by hindlimb or upper body movements, but not by the head movements that signalled interruption of eating.
A programmable integrated circuit controlled the feeding schedule, timing, location, and intensity of thermal stimuli, and the activation of 3 responselatency counters. Periodic illumination of the food cup signaled the onset of 1 of 4315 -s food-available periods, 32 of which were used for data collection. The program advanced only when the cat's muzzle entered the food cup. Interruption of photocell contact triggered stimuli on 22 of the food-available periods so that thermal stimulation was coincident with eating; 10 stimuli were non-coincident with food delivery. Interrupt responses to non-coincident stimuli occured when the cat's muzzle was in the empty cup. During each session, 12 stimuli were blank trials at $38{ }^{\circ} \mathrm{C}, 12$ were at an intermediate temperature $\left(43-51{ }^{\circ} \mathrm{C}\right)$, and 8 were at the highest temperature selected for that session $\left(51-60^{\circ} \mathrm{C}\right)$. Four of the blank and intermediate stimuli and two of the higher intensity stimuli were not coincident with eating. The length of the interstimulus interval depended on the rate at which each cat advanced the program by responding to the illuminated food cup. The shortest possible session was approximately $30 \mathrm{~min}$ long, giving a minimum interstimulus interval of $1.5 \mathrm{~min}$ (not including blank trials). Some cats took $1 \mathrm{~h}$ to advance through the program, thus doubling the average interstimulus interval. The stimulus sequence was based on a random order ${ }^{25}$ of intensity and laterality, modified to assure that high-intensity pulses could not be delivered to the same site at intervals shorter than $3 \mathrm{~min}$. The frequency, duration, and intensity of noxious stimuli delivered according to the above schedule was well within tolerance because all cats readily accepted daily placement in the apparatus and regularly activated advancement of the stimulus delivery program.

At stimulus onset, 3 response-latency counters were started. A pulse from a comparator circuit stopped the appropriate counter when the output of the microphone or movement detector amplifier exceeded a selected level. Photocell activation stopped the interupt-detection counter when the cat's muzzle was withdrawn from the food cup. Response latencies were read from the digital display. Any response could abort the stimulus.

\section{Data analysis}

Response latencies between 0.5 and $7 \mathrm{~s}$ after each 
stimulus pulse onset were entered into disk files of a Data General Nova 3/12 laboratory computer for the computation of response probabilities, the mean \pm S.D. of the response latency for each stimulus temperature, and the construction of response latency histograms for each temperature trial. The variance about each response probability was expressed as the standard error and significant differences between probabilities were determined by computing the $95 \%$ confidence intervals of each probability $^{28}$. For probabilities based on less than 30 trials, we used the tables computed by $\mathrm{Crow}^{22}$.

Responses to coincident and non-coincident stimuli were analyzed separately; a significant difference between these probabilities was interpreted as foodinduced response modulation. Analyses of response trends were obtained by sequentially computing the response probabilities for each temperature in blocks of 3 days.

\section{Surgery and postoperative care}

Each cat was deeply anesthetized with $50 \mathrm{mg} / \mathrm{kg}$ of pentobarbital i.v. Supplemental doses were given as needed to maintain complete suppression of flexor reflexes to intense mechanical stimuli.

Under aseptic conditions, a temperature-controlled probe with a $1 \mathrm{~mm}$ tip heated by radio frequency current (Radionic Model RFG-4, Burlington, MA, U.S.A.) was inserted into the medial medulla through a craniotomy in the occipital bone. After the desired location of the tip was attained, the temperature of the tip was raised to the selected level over a 1-min period and maintained at that temperature for another minute before turning off the heating current. Maximum probe tip temperature ranged between 60 and $65{ }^{\circ} \mathrm{C}$ among cats, depending on the size of the lesion desired. One cat received a unilateral paramedial lesion. Bilateral paramedial lesions were placed in one cat, and 4 cats received combined paramedial and midline lesions.

Each cat was given antibiotics intramuscularly daily for one week after surgery and received sterile water subcutaneously during the immediate postoperative recovery period as needed. Postoperatively, cats maintained their body weight and normal food consumption, appeared active and alert, and responded affectionately to petting and handling. All cats exercised freely outside their cages daily.

\section{Histology}

Each cat received deep pentobarbital anesthesia followed by transcardiac perfusion of the entire body with normal saline and $10 \%$ formalin in saline. The hindbrain was removed and steeped in $10 \%$ formal saline for 1 week before sectioning on a freezing microtome. After removing the dura, 50 frozen sections were stained by the Nissl method. The location and extent of the lesion in each case was determined by drawings of the images of the coronal sections projected onto appropriate coronal plates of the Berman ${ }^{6}$ atlas. These drawings were then used to reconstruct the lesion onto the parasagittal plates of the same atlas.

\section{RESULTS}

\section{Preoperative testing}

Six cats were tested for responses to thermal stimulation of the hindlimbs with stimulus temperatures ranging from 43 to $60^{\circ} \mathrm{C}$. An average of $80 \pm$ 26 (S.D.) stimuli were delivered at each temperature to each cat during preoperative testing.

All cats showed significant increases in the probability of two or more behaviors as stimulus temperature increased. Fig. 1 shows the preoperative stimulus-response profiles of two of the most frequently emitted behaviors for each cat. These preoperative response profiles are also shown with

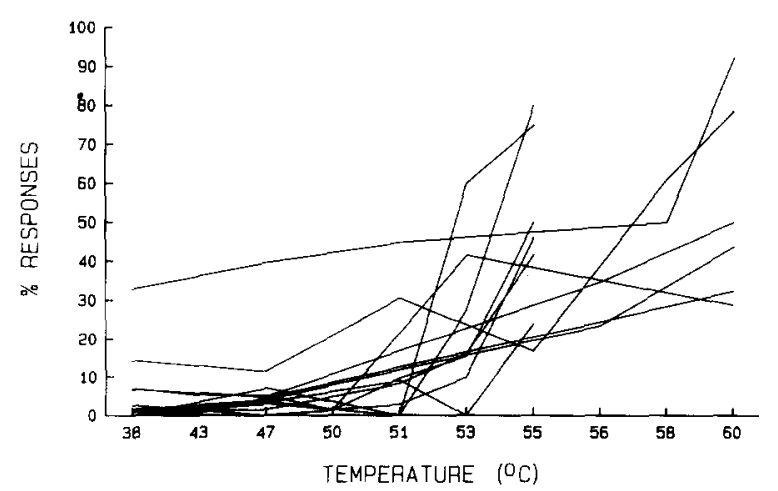

Fig. 1. Preoperative stimulus-reponse profiles of two behaviors for each of 6 cats. In this figure and Figs. 4 and 6, the ordinate shows the percentage of trials which elicited the behavioral response. Three cats gave very few responses to stimuli delivered coincident with food and were therefore tested with $60^{\circ} \mathrm{C}$ stimuli. The profiles shown here include interrupt, movement, and vocalization responses to foodcoincident and non-coincident stimuli. 
comparable postoperative responses for each cat in Figs. 4 and 6 . Three cats (B, $O$ and $R$ ) emitted very few responses when stimuli were coincident with food delivery and consequently were tested with temperatures up to $60^{\circ} \mathrm{C}$ in an attempt to overcome this response suppression. The remaining 3 cats responded to both coincident and non-coincident stimulus temperatures of $55^{\circ} \mathrm{C}$ or less. All cats emitted interrupt responses, $5(\mathrm{O}, \mathrm{R}, \mathrm{E}, \mathrm{C}$ and $\mathrm{T}$ ) gave movement responses and $5(\mathrm{O}, \mathrm{B}, \mathrm{E}, \mathrm{C}$ and $T$ ) vocalized in response to noxious thermal stimuli,

Response threshold was defined as the lowest temperature at which the response probability exceeded that at the adapting temperature $\left(38^{\circ} \mathrm{C}\right)$ by an amount sufficient to exclude each probability from the $95 \%$ confidence boundary of the other. This criterion was used to compare responsiveness at all other test temperatures and to identify significant differences in responsiveness. By this criterion, response threshold ranged from 47 to $51{ }^{\circ} \mathrm{C}$ for one or more behavior for each of 6 cats. For all cats, response latency ranged from an average of $2.67 \pm$ 0.20 (S.E.M.) s for interrupt responses to coincident stimuli to $1.95 \pm 0.30$ (S.E.M.) s for movement responses to non-coincident stimuli.

Trends of responsiveness were examined by determining the response probability at the threshold temperature for sequential blocks of 3 days for each cat. Regrèssion analysis revealed no significant relationship between time and response probability for any cat (Kendall rank correlation; $P \geqslant 0.24)$.

Each cat showed a food-induced suppression of one or more behaviors. As noted in our previous studies $^{17,18}$, this modulation was more pronounced at higher stimulus temperatures. Fig. 2 shows the individual and average preoperative food-induced modulation profiles. As would be expected at stimulus temperatures below the noxious range, the probability of a response to a stimulus that is coincident with food $\left(P_{\mathrm{c}}\right)$ is slightly less than when food and stimulation are non-coincident $\left(P_{n}\right)$. However, as stimulus intensity increases into the noxious range, the difference between these probabilities increases, showing that the presentation of food suppresses the frequency of nocifensive responses by 30-60\% (Fig. 2).

\section{Postoperative testing}

All cats were allowed at least 18 days for recovery from surgery before postoperative testing began. At the time testing resumed, and throughout the remaining testing period of at least 5 weeks, each cat was consuming sufficient water and food to maintain hydration and preoperative body weight. Sleeping time and pattern were not monitored, but each cat appeared alert, normally responsive to petting and all other natural environmental stimuli, and to have a normal level of spontaneous motor activity. There was no obvious disturbance of gait; each cat was observed to leap up and down heights of at least 3 feet and to walk along narrow surfaces without apparent difficulty.

An average of $70 \pm 29$ (S.D.) stimuli were delivered at each temperature to each cat during the postoperative testing period.

Lesions limited to gigantocellular tegmental field (FTG) and magnocellular tegmental field (FTM)

Four cats had either unilateral (cat $O$ ), bilateral (cat R), or midline plus unilateral (cats B and $\mathrm{T}$ ) thermal lesions of the medial medullary reticular formation. In each case, portions of the magnocellular and gigantocellular reticular formation were destroyed, but the ventral raphe nuclei (postpyramidal raphe ${ }^{6}$, N. raphe pallidus ${ }^{67}$ ) were spared (Fig. 3). According to the cytoarchitectural terminology used by Taber $^{67}$, the lesions involved the nuclei

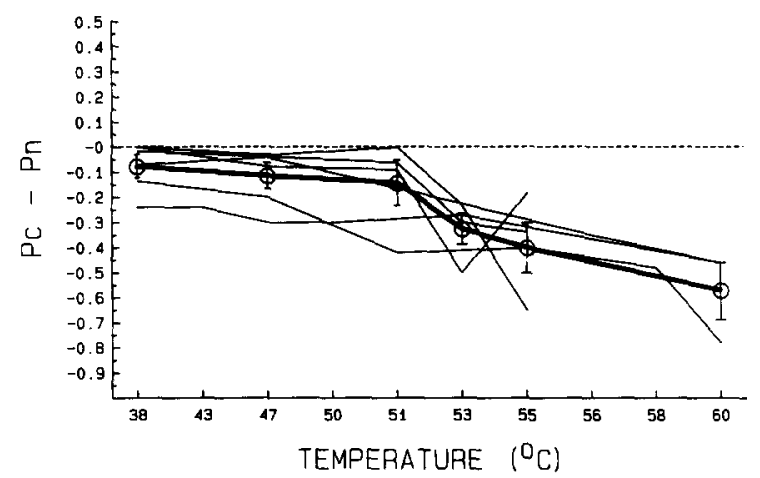

Fig. 2. Preoperative response modulation profiles of 6 cats. $P_{c}$ $=$ probability of a response to a thermal stimulus delivered coincident with food. $P_{\mathrm{n}}=$ probability of a response to a thermal stimulus that is non-coincident with food delivery. Open circles with heavy line: average \pm S.E.M. Response suppression increases with increasing stimulus temperatures. 
medullae oblongotae centralis, paramedium reticularis, intercalatus, and the caudal part of nucleus gigantocellularis. Parts of the most dorsal nucleus centralis inferior ${ }^{6}$, the nuclei raphe magnus and obscurus $^{67}$ and the medial longitudinal fasciculus were also destroyed in all but cat $\mathrm{O}$.

Every cat except one showed a significant decrease in the probability of each previously emitted nocifensive behavior. The exception, cat $T$, showed a marked decrease in both interrupt and vocalization responses, but movement responses were not significantly affected. Fig. 4 shows examples of the shift
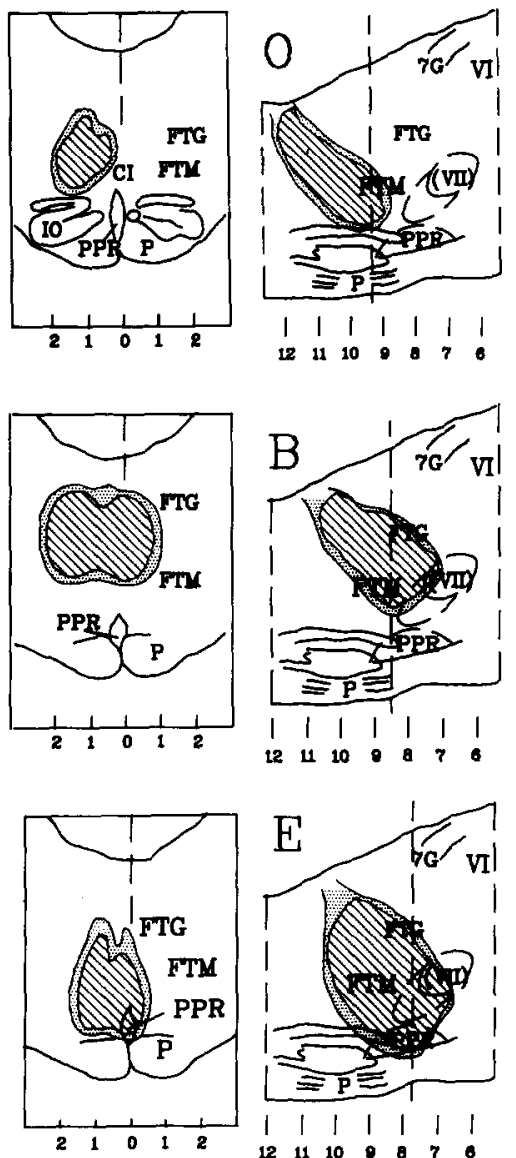

in some of the nocifensive response profiles of each cat.

In addition to the response changes shown in Fig. 4 , cat $\mathrm{O}$ had a significant decrease in interrupt and movement responses to coincident stimuli and an attenuation of vocalization responses to non-coincident stimuli; cat B also showed a significant decrease in interrupt responses to non-coincident stimuli.

Because of the marked decrease in the probability of many of these responses, threshold changes could be estimated for only two cats ( $O$ and $B)$, both showing increases of $5-8{ }^{\circ} \mathrm{C}$. No significant changes
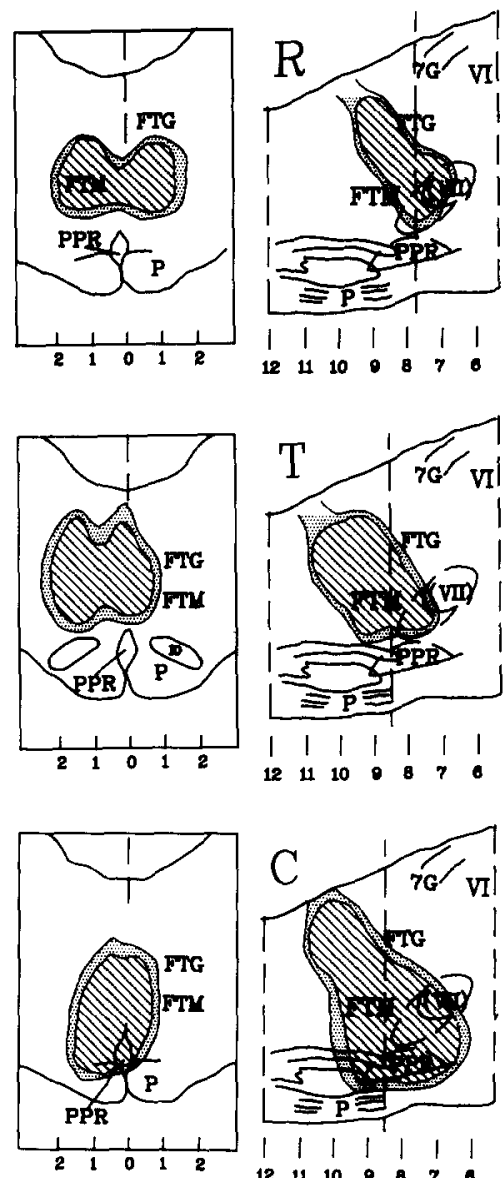

Fig. 3. Reconstruction of thermocoagulation lesions. Coronal and parasagittal sections are shown for each cat (O, R, B, T, E and C). Stereotaxic coordinate numbers and drawings of parasagittal sections are from the atlas by Berman ${ }^{6}$. The parasagittal section is $1.2 \mathrm{~mm}$ from midline and shows the projected location of the seventh nerve nucleus $(2.9-3.7 \mathrm{~mm}$ from midline) and the postpyramidal raphe nucleus $(0.2-0.4 \mathrm{~mm}$ from midline). Coronal drawings are tracings of coronal sections; serial coronal sections were used to reconstruct each lesion projected onto the standard parasagittal drawings. Vertical dashed lines on parasagittal drawings show the level of coronal sections. Cross-hatched area: complete tissue necrosis and gliosis. Stippled area: loss of neuronal staining (Nissl) and glial proliferation. Note that only cats $\mathrm{E}$ and $\mathrm{C}$ had lesions that extended into the postpyramidal raphe nucleus (PPR). Abbreviations $\left(\right.$ Berman $^{6}$ ): CI, n. centralis inferior; FTG, gigantocellular tegmental field; FTM, magnocellular tegmental field; IO, inferior olivary nucleus; $P$, pyramidal tract; PPR, postpyramidal raphe nucleus; VI, 6th nerve nucleus; VII, 7th nerve nucleus; $7 G$, genu of 7 th nerve. 
in response latency could be detected for any behavior of any cat. The change in average latency ranged from an increase of $0.8 \mathrm{~s}$ for vocalization to a decrease of $0.4 \mathrm{~s}$ for movement responses. However, postoperative latency measurements could not be made for each behavior because the lesion completely eliminated some of the responses (Fig. 4).

All cats continued to show food-induced suppression of responsiveness postoperatively (Fig. 5). We could not determine whether lesions of a particular size or location caused a change in the degree of response modulation. Modulation appeared to be decreased, but was not eliminated in 2 cats ( $O$ and R, Fig. 5); however, 2 other cats with larger and similarly located lesions showed no changes in modulation at all (cats B and T, Fig. 5).

\section{Lesions involving ventral raphe nuclei}

Two cats received lesions that destroyed portions of the magnocellular and gigantocellular reticular formation and most of the postpyramidal raphe nucleus $\left(\mathrm{PPR}^{6}\right.$, n. raphe pallidus ${ }^{67}$ ) throughout its
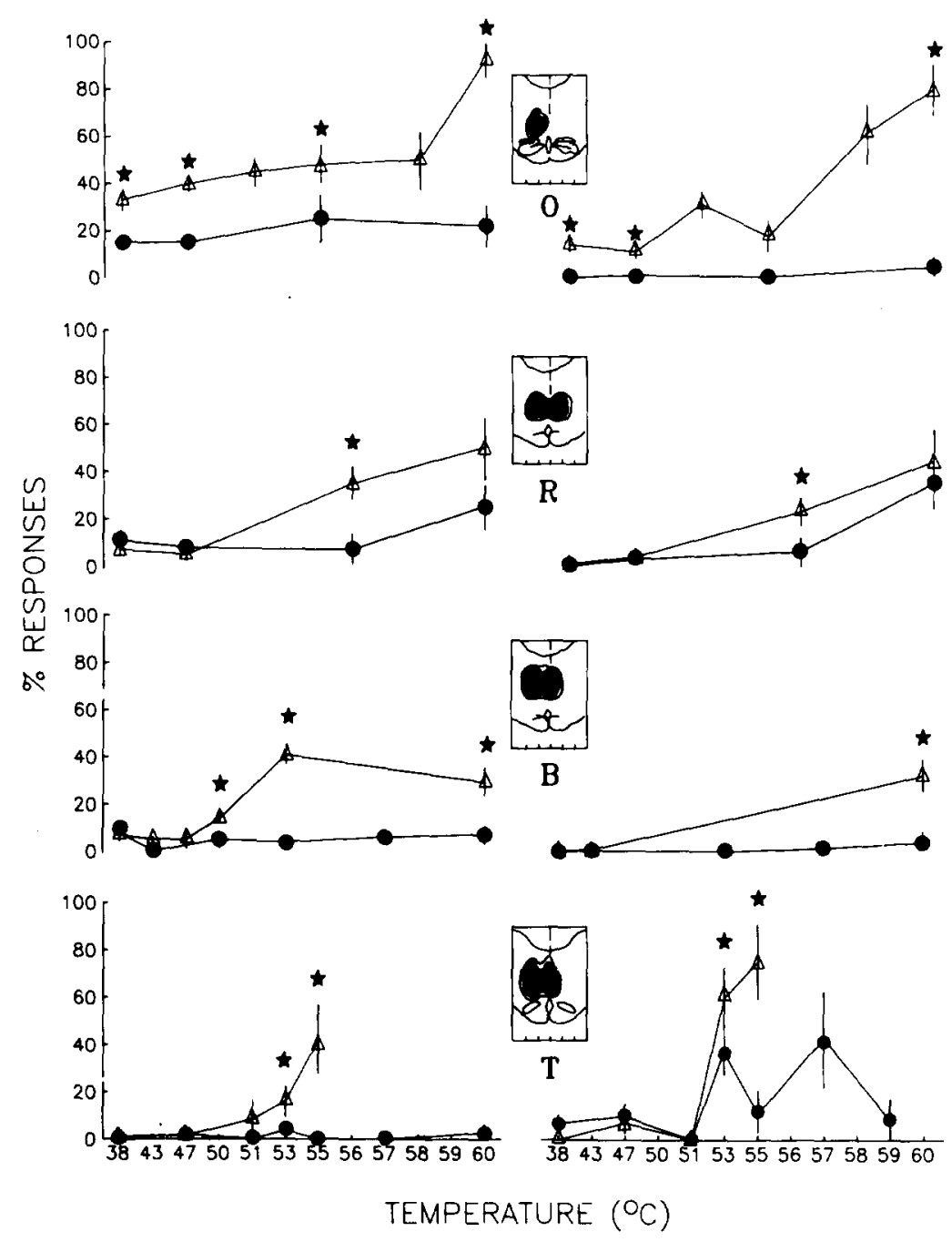

Fig. 4. Shift of stimulus-response profiles in 4 cats $(O, R, B$ and $T)$ with lesions that spared the postpyramidal raphe nucleus (PPR). Lesion location is indicated by cross-hatched area in drawings of medullary coronal sections. Open triangles: average ( \pm S.E.M.) preoperative \% responses. Filled circles: postoperative responses. Stars indicate that prelesion and postlesion averages are outside each other's $95 \%$ confidence boundary. Interrupt response profiles are shown on the left. On the right, response profiles are shown for movement $(O$ and $R$ ) and vocalization ( $B$ and $T$ ). Medullary reticular formation lesions that spared the PPR reduced responsiveness to noxious thermal stimuli. 


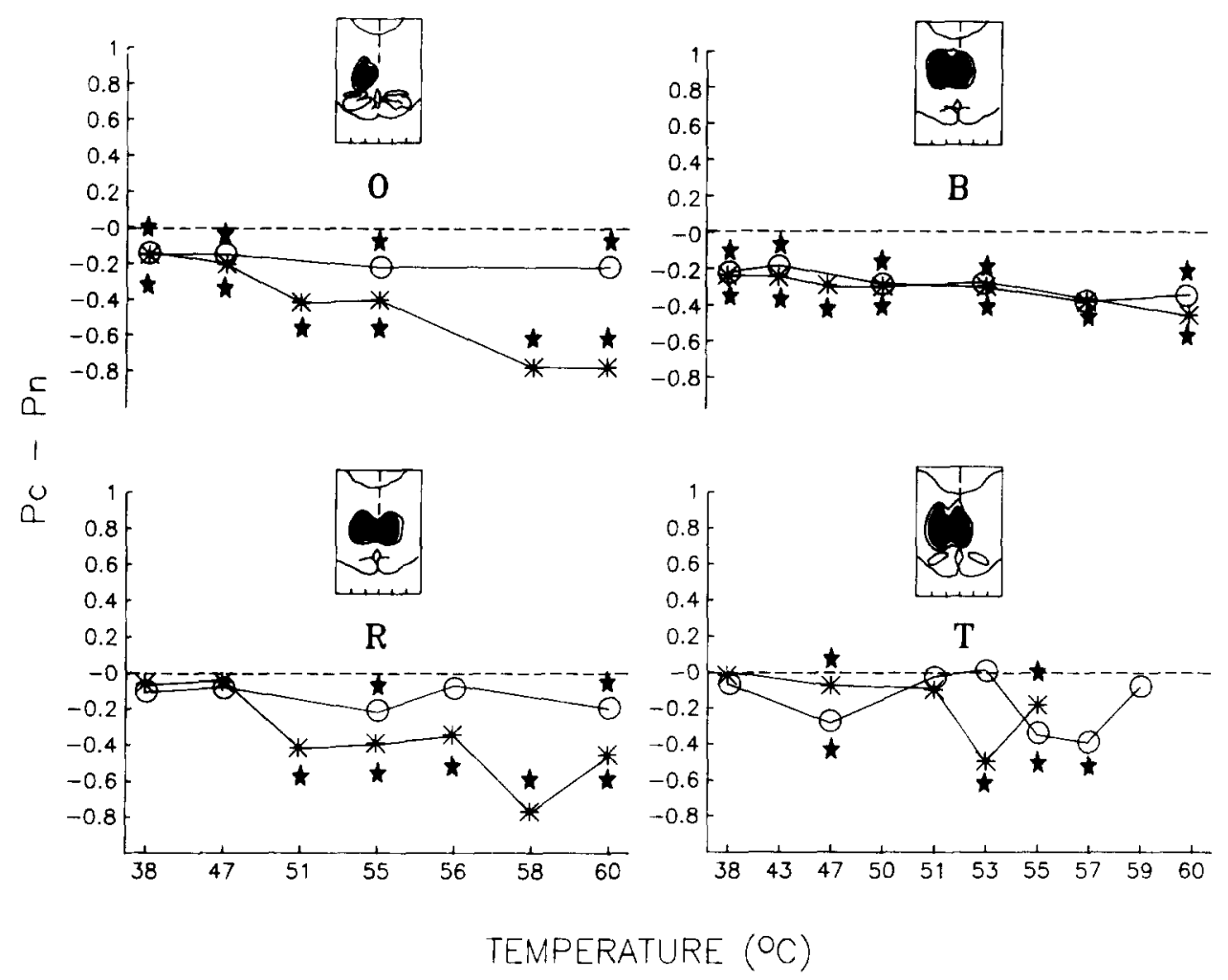

Fig. 5. Response modulation profiles (as in Fig. 2) of the 4 cats whose response profiles are shown in Fig. 4. Asterisks: preoperative modulation. Open circles: postoperative modulation. Stars near each data point indicate that response suppression has occurred because the probabilities of responses to food-coincident stimuli $(P c)$ and to non-coincident stimuli $(P n)$ are outside each others's 95\% confidence boundary. Modulation of interrupt $(O, B$ and $R)$ and of movement responses $(T)$ are shown. Food-induced response suppression persists after lesions that decreased noncifensive responsiveness (Fig. 4).

length (cats $E$ and $C$, Fig. 3). Except for the involvement of the PPR, the lesions in cats $E$ and $C$ considerably overlapped the region destroyed by the lesions in cats $O, R, B$ and $T$.

Both cats showed significant increases in interrupt and movement responses to coincident stimuli and in movement responses to non-coincident stimuli (Fig. 6). Vocalization responses were emitted at approximately the same significant probability as preoperatively. The threshold for emitting any nocifensive response remained unchanged at $51^{\circ} \mathrm{C}$ for cat $\mathrm{E}$ and decreased from 51 to $47^{\circ} \mathrm{C}$ for cat $\mathrm{C}$. There were no significant changes in the latency of any response for either cat.

Both cats continued to show food-induced suppression of responses (Fig. 7). Indeed, the cat with the most extensive destruction of the PPR (cat $C$, Fig. 3) showed increased phasic response suppression postoperatively.

\section{DISCUSSION}

\section{Lesions confined to FTG and FTM}

These medial medullary lesions spared the medial lemniscus, pyramidal tracts and the most ventral raphe nuclei (PPR) but destroyed cells and nerve fibers within varying portions of the magnocellular and gigantocellular reticular fields as defined by Berman ${ }^{6}$. Supraspinal nocifensive responsiveness was reduced without a measurable effect on response latency or any clinically evident effect on motor function. Furthermore, increased nocifensive responsiveness was seen when the lesion was extended into the ventral raphe PPR. These results show that the FTG and FTM lesions did not destroy sensory or motor mechanisms that are necessary for nocifensive responses and that the neurons and axons of passage destroyed by the lesions facilitate these responses but are not necessary for their execution. 


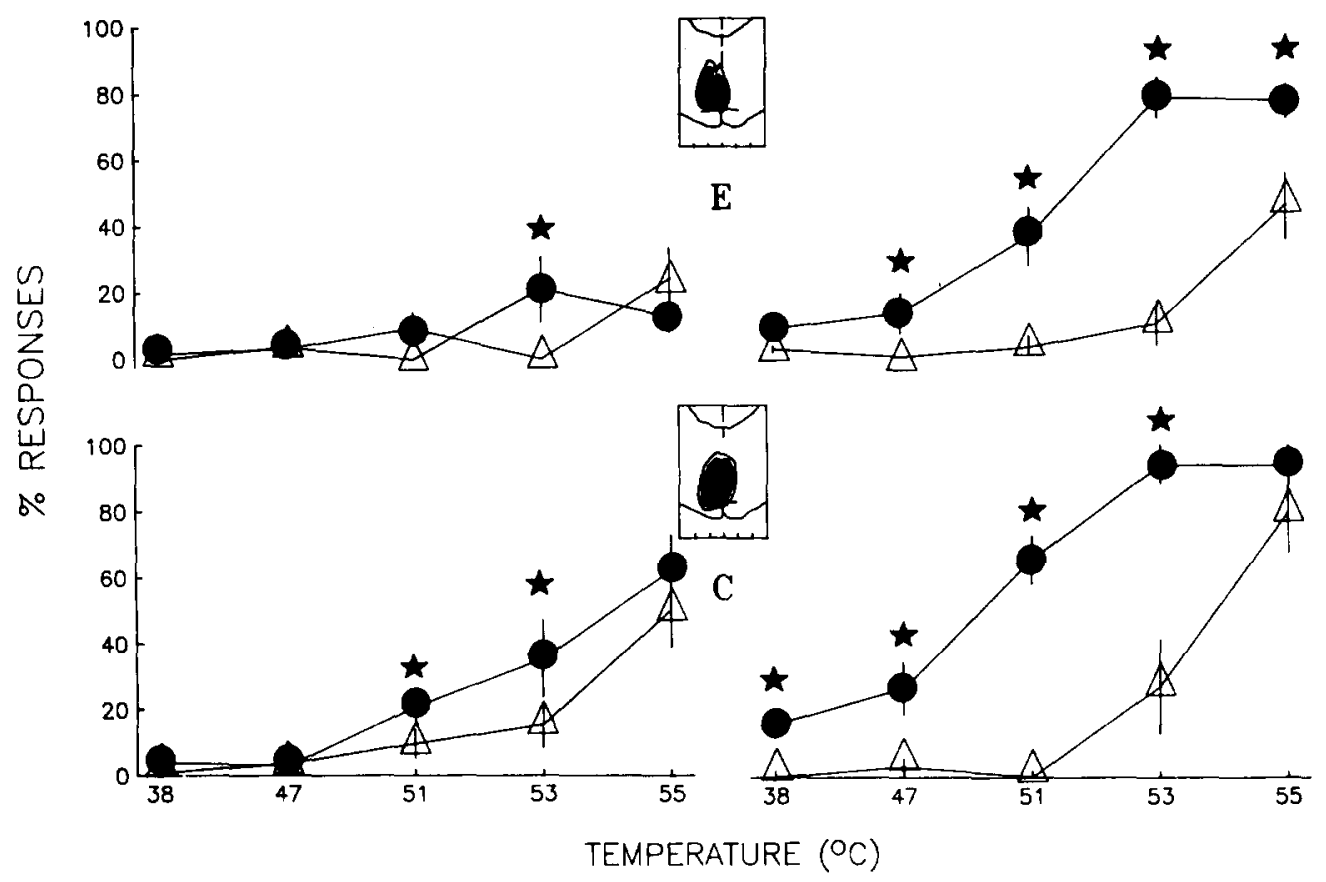

Fig. 6. Shift of stimulus-response profiles in two cats (E and $C$ ) with lesions that destroyed the postpyramidal raphe nucleus (PPR). Conventions are the same as in Fig. 4. Interrupt response profiles are shown on the left, movement response profiles on the right. Medullary reticular formation lesions that destroyed the PPR increased responsiveness to noxious thermal stimuli.

Our results are in accord with those reported by Halpern and Halverson ${ }^{38}$ and by Anderson and Pearl $^{2}$ for the cat. Zemlan et al. $^{74}$ also reported analgesia on tests of supraspinal, but not spinal reflex, nocifensive responses in the rat after lesions within the gigantocellular and magnocellular reticular formation. Hammond ${ }^{40}$ found that similar lesions impaired the acquisition of a conditioned emotional response in the rat. Mohrland et al. ${ }^{47}$, however, found that paramedian gigantocellular lesions attenuated analgesia produced by morphine microinjected into the midbrain but had no effect on hot plate or tail flick responses in the rat.

\section{Lesions extending into the PPR}

The PPR as defined by Berman ${ }^{6}$ and presented in his atlas is composed primarily of cells forming the nucleus raphe pallidus (NRP) ${ }^{67}$ but probably includes the ventral part of nucleus raphe obscursus caudally and the ventral part of nucleus raphe magnus (NRM) rostrally. When the lesion extended ventrally to destroy this region (cats $E$ and $C$ ), nocifensive responsiveness increased. The results obtained with lesions limited to the FTG and FTM suggest that this increase was superimposed on a

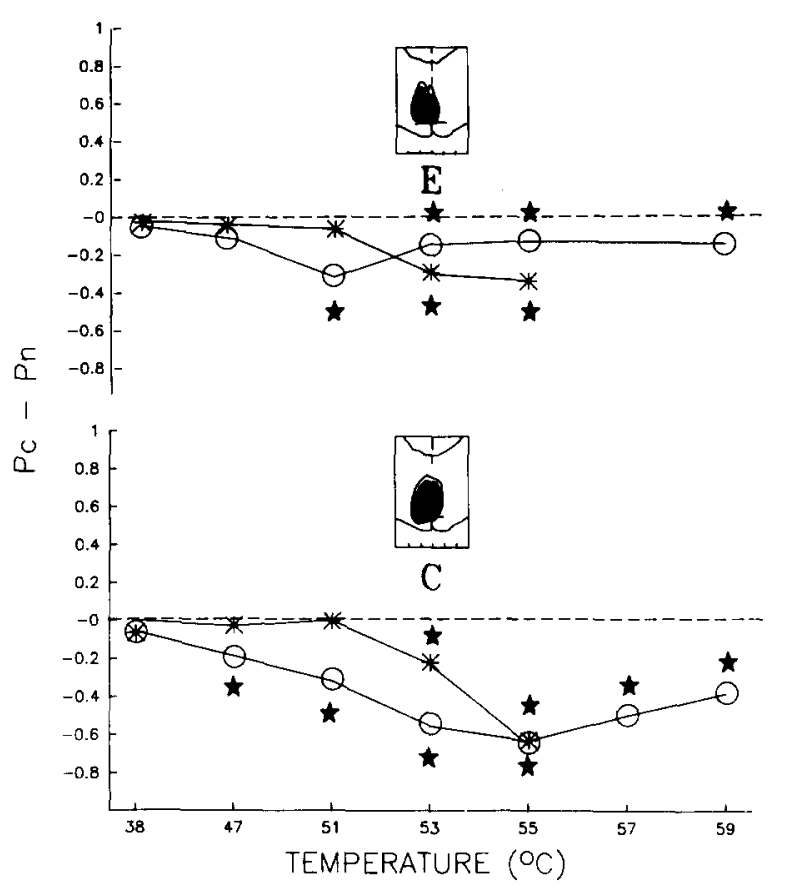

Fig. 7. Response modulation profiles of the two cats whose response profiles are shown in Fig. 6. Conventions are the same as in Fig. 5. Modulation of movement responses are shown. Food-induced response suppression persists after lesions that increased nocifensive responsiveness (Fig. 6). 
background of decreased responsiveness and that lesions confined to the PPR would produce an even greater increase in responsiveness. In extending our lesions into the ventrally located PPR, we also damaged more of the dorsally situated central inferior nucleus than was involved in the cats with sparing of the PPR. Therefore, we cannot be certain whether the contrasting effect of these larger lesions is due to the additional destruction of ascending and descending pathways from $\mathbf{n}$. centralis inferior or to the involvement of PPR neurons with predominantly caudally projecting axons.

To our knowledge, there are no comparable studies of the effect of ventral medullary raphe lesions on supraspinally mediated nocifensive responses of the cat. Abbott et al. ${ }^{1}$ found that midline lesions in the midbrain, pons or medulla had no effect on either the supraspinally mediated formalin test or the tail flick reflex in the rat. Their lesions, however, may have spared much of the more caudal and ventral NRP. Our results support and extend the observation that lesions of the NRM and NRP in the unanesthetized, decerebrate cat markedly reduce the threshold and latency of the hindlimb withdrawal reflex to noxious pinch or heat ${ }^{72}$ and that NRM and NRP lesions decrease the tail flick reflex latency in the rat $^{57,58}$ (however, see Watkins et al. ${ }^{70}$ ).

\section{Neural mechanisms: tonic and phasic modulation}

Neither the PPR nor the FTM and FTG lesions eliminated the phasic, food-induced modulation of nocifensive responses. This result, combined with similar findings in our study of the effect of feline spinal tractotomies ${ }^{18}$, suggests strongly that the neural mechanisms mediating this phasic modulation are organized at a suprabulbar level. The tonic excitability of nocifensive responses, however, was affected by both types of lesions and must therefore be determined, in large part, by medial and midline medullary reticular formation neurons or axons passing through these regions.

The FTG appears to be the major source of rostral projections to the midbrain and diencephalon from the medial medullary reticular formation in the rat $^{52,69,75}$ and $\mathrm{cat}^{8,50}$. Both the FTM and FTG also send axons caudally to the spinal cord, the FTG projecting primarily to motor, and the FTM to sensory, nuclei ${ }^{3,4}$. In the rat, Martin et al. ${ }^{45}$ have presented evidence for FTG projections to dorsal horn laminae I and II as well as to deeper laminae.

A majority of the neurons recorded from both the FTM and FTG have been shown to respond differentially to noxious somatic stimuli ${ }^{10,14,15,31,33,44}$, 49.51,71 (however, see Saade et al. ${ }^{59}$ ). Neurons within this same region participate in spinal motor ${ }^{24,54,65}$ and reflex functions ${ }^{21,22,63,64}$. Electrical stimulation in the medial medullary reticular formation suppresses the nociceptive responses of spinal dorsal horn neurons $\mathrm{s}^{29,37,55}$, excites or inhibits spinothalamic tract neurons ${ }^{32,34,35}$ suppresses nociceptive brainstem $^{20}$ and spinal reflexes ${ }^{61}$ and elicits aversive behavioral responses ${ }^{12,13}$. The functional role of this medial bulboreticular region in pain mechanisms has been a subject of speculation elsewhere ${ }^{9,16,65}$. Our results suggest that the net effect of both the rostral and caudal projections originating in or passing through this area is to facilitate tonically supraspinally organized nocifensive responses.

In contrast, it appears that neurons in the ventral midline raphe tonically suppress nocifensive behavior. Anatomical evidence shows that neurons in the central inferior nucleus ${ }^{6}$ or $\mathrm{NRM}^{67}$ have direct rostral projections to medial and intralaminar thalamic nuclei that receive nociceptive input ${ }^{53}$. The NRP, which corresponds most closely with the PPR of Berman ${ }^{6}$, appears to have few, if any, diencephalic or other rostral projections ${ }^{52,53}$. Both of these raphe nuclei, however, send substantial projections to the spinal cord in cat and rat, the NRM primarily by dorsal, and the NRP by ventral, bulbospinal pathways $^{3,46}$.

There is conflicting evidence on the behavioral effect of lesions within the medullary raphe nuclei. Most investigators find no effect of NRM lesions on spinally mediated ${ }^{1,5,11,43,70}$ or supraspinally mediated $^{1}$ nocifensive responses in the rat. However, others have shown that electrolytic lesions or local anesthetic blockade in the NRM and NRP lowers the threshold for the tail flick reflex in the rat $^{42,56-58,62}$ and markedly increases the excitability of a cutaneous flexion reflex in the unanesthetized decerebrate cat $^{72}$. Neurophysiological experiments have shown that reversible or permanent inactivation of medullary raphe neurons does not affect the tonic descending inhibition of dorsal horn neurons in the rat or $\mathrm{cat}^{30,36,37,42}$. Jones and Gebhart ${ }^{42}$, in fact, 
saw transient (less than $10 \mathrm{~min}$ ) decreases in noxious heat-evoked activity of rat dorsal horn neurons after lidocaine blockade of the NRM. Sandkuhler et al. ${ }^{60}$, however, have shown that bilateral lidocaine block of the rostral lumbar lateral funiculi enhances the nociceptive responses of caudal lumbar dorsal horn neurons and reduces the inhibition of these responses produced by stimulation within the NRM or periaqueductal gray. The weight of current evidence $^{7,29,39}$ thus appears to favor the hypothesis that activation of certain bulbar raphe spinal neurons attenuates nociceptive transmission within the dorsal horn; this hypothesis best explains our results.

The results of experiments on ascending NRM activity fail to show an effect of NRM lesions on nocifensive behavior. Taylor ${ }^{68}$ has shown that NRM lesions abolish the responses of hypothalamic or ventrobasal thalamic neurons to innocuous thermal stimulation of the rat's scrotum. This result supports other evidence that some NRM neurons in the rat form part of an ascending thermoregulatory

\section{REFERENCES}

1 Abbot, F.V., Melzack, R. and Samuel, C., Morphine analgesia in the tail-flick and formalin pain tests is mediated by different neural systems, Exp. Neurol., 74 (1982) 644-651.

2 Anderson, K.V. and Pearl, G.S., Long term increases in nociceptive thresholds following lesions in feline nucleus reticularis gigantocellularis. Abstract, First World Congress of Pain, IASP, Florence, 1975.

3 Basbaum, A.I. and Fields, H.L., The origin of descending pathways in the dorsolateral funiculus of the spinal cord of the cat and rat: further studies on the anatomy of pain modulation, J. Comp. Neurol., 187 (1979) 513-532.

4 Basbaum, A.I., Clanton, C.H. and Fields, H.L., Three bulbospinal pathways from the rostral medulla of the cat: an autoradiographic study of pain modulating systems, $J$. Comp. Neurol., 178 (1978) 209-224.

5 Behbehani, M.M. and Fields, H.L., Evidence that an excitatory connection between the periaqueductal gray and nucleus raphe magnus mediates stimulation-produced analgesia, Brain Research, 170 (1979) 85-93.

6 Berman, A.L., The Brain Stem of the Cat, Univ. Wisconsin Press, Madison, 1968, $175 \mathrm{pp}$.

7 Besson, J.-M. and Chaouch, A., Descending serotoninergic systems. In H. Akil and J.W. Lewis (Eds.), Neurotransmitters and Pain Control, Karger, Basel, 1987, pp. 64-100.

8 Bowsher, D., Mallart, A., Petit, D. and Albe-Fessard, D., A bulbar relay to the centre median, $J$. Neurophysiol., 31 (1968) 288-300.

9 Bowsher, D., Role of the reticular formation in responses to noxious stimulation, Pain, 2 (1976) 361-378.

10 Burton, H., Somatic sensory properties of caudal bulbar pathway $^{23,41,73}$ which appears to have little or no relevance to nociceptive mechanisms or nocifensive behavior.

In summary, our results and the available evidence suggest that supraspinally organized nocifensive responses are: (1) tonically facilitated by neural activity originating in or passing through the medial bulboreticular formation; and (2) tonically suppressed by midline raphe spinal neurons. These tonic modulating influences appear to be independent of a superimposed, behaviorally related, phasic modulation that is organized at a suprabulbar level.

\section{ACKNOWLEDGEMENTS}

The technical assistance of Rosalie Tocco, Linda Sorkin, Lawrence Cronin, and Patricia Morris Walsworth is greatly appreciated. Gabriel Frommer provided valuable advice. This study was supported by grants from the Veterans Administration, NIH (NINCDS), and the Bristol Myers Corporation.

reticular neurons in the cat (Felis domestica), Brain Research, 11 (1968) 357-372.

11 Cannon, J.T., Lewis, J.W., Weinberg, V.E. and Liebeskind, J.C., Evidence for the independence of brainstem mechanisms mediating analgesia induced by morphine and two forms of stress, Brain Research, 269 (1983) 231-236,

12 Carr, K.D. and Coons, E.E., Lateral hypothalamic stimulation gates nucleus gigantocellularis-induced aversion via a reward-independent process, Brain Research, 232 (1982) 293-316.

13 Casey, K.L., Escape elicited by bulboreticular stimulation in the rat, Int. J. Neurosci., 2 (1971) 29-34.

14 Casey, K.L., Responses of bulboreticular units to somatic stimuli eliciting escape behavior in the cat, Int. J. Neurosci., 2 (1971) 15-28.

15 Casey, K.L., Somatic stimuli, spinal pathways, and size of cutaneous fibers influencing unit activity in the medial medullary reticular formation, Exp. Neurol., 25 (1969) $35-56$.

16 Casey, K.L., The reticular formation and pain: toward a unifying concept. In J.J. Bonica (Ed.), Pain (ARNMD), Raven, New York, 1980, pp. 93-105.

17 Casey, K.L. and Morrow, T.J., Nocifensive responses to cutaneous thermal stimuli in the cat: stimulus-response profiles, latencies, and afferent activity, J. Neurophysiol., 50 (1983) 1497-1515.

18 Casey, K.L. and Morrow, T.J., Supraspinal nocifensive responses of cats: spinal cord pathways, monoamines, and modulation, J. Comp. Neurol., 270 (1988) 591-605.

19 Casey, K.L. and Morrow, T.J., Supraspinal pain mechanisms in the cat. In R.L. Kitchell and H.H. Erickson (Eds.), Animal Pain Perception and Alleviation, Waverly, Baltimore, 1983, pp. 63-81.

20 Chan, S.H.H., Suppression of dental pulp-evoked trigem- 
inal responses by nucleus reticularis gigantocellularis in the cat, Exp. Neurol., 66 (1979) 356-364.

21 Chan, S.H.H. and Barnes, C.D., A critical reticular site involved in the spino-bulbospinal reflex system, Pflügers Arch., 357 (1975) 313-321.

22 Crow, E.L., Confidence intervals for a proportion, Biometrika, 43 (1956) 423-435.

23 Dickenson, A.H., Specific responses of rat raphe neurones to skin temperature, J. Physiol. (Lond.), 273 (1977) 277-293.

24 Drew, T., Dubic, R. and Rossignol, S., Discharge patterns of reticulospinal and other reticular neurons in chronic, unrestrained cats walking on a treadmill, J. Neurophysiol., 55 (1986) 375-401.

25 Fellows, B.J., Chance stimulus sequences for discrimination tasks, Psychol. Bull., 67 (1967) 87-92.

26 Fields, H.L. and Basbaum, A.I., Brain stem control of spinal pain-transmission neurons, Annu. Rev. Physiol., 40 (1978) 217-248.

27 Fields, H.L., Bry, J., Hentall, I. and Zorman, G., The activity of neurons in the rostral medulla of the rat during withdrawal from noxious heat, $J$. Neurosci., 3 (1983) 2545-2552.

28 Freund, J.E., Mathematical Statistics, Pretentice-Hall, Englewood Cliffs, NJ, 1962, 390 pp..

29 Gebhart, G.F., Modulatory effects of descending systems on spinal dorsal horn neurons. In T.L. Yaksh (Ed.), Spinal Afferent Processing, Plenum, New York, 1986, pp. 391416.

30 Gebhart, G.F., Sandkuhler, J., Thalhammer, J.G. and Zimmerman, M., Inhibition of spinal nociceptive information by stimulation in midbrain of the cat is blocked by lidocaine microinjected in nucleus raphe magnus and medullary reticular formation, $J$. Neurophysiol., 50 (1983) 1446-1459.

31 Goldman, P.L., Collins, W.F., Taub, A. and Fitzmartin, J., Evoked bulbar reticular unit activity following A delta fiber stimulation of somatosensory nerves in cat, Exp. Neurol., 37 (1972) 597-606.

32 Giesler, G.J., Yezierski, R.P., Gerhart, K.D. and Willis, W.D., Spinothalamic tract neurons that project to medial and/or lateral thalamic nuclei: evidence for a physiologically novel population of spinal cord neurons, J. Neurophysiol., 46 (1981) 1285-1307.

33 Guilbaud, G., Besson, J.M., Oliveras, J.L. and WyonMaillard, M.C., Modifications of the firing rate of bulbar reticular units (nucleus gigantocellularis) after intra-arterial injection of bradykinin into limbs, Brain Research, 63 (1973) 131-140.

34 Haber, L.H., Martin, R.F., Chatt, A.B. and Willis, W.D., Effects of stimulation in nucleus reticularis gigantocellularis on the activity of spinothalamic tract neurons in the monkey, Brain Research, 153 (1978) 163-168.

35 Haber, L.H., Martin R.F., Chung, J.M. and Willis, W.D., Inhibition and excitation of primate spinothalamic tract neurons by stimulation in region of nucleus reticularis gigantocellularis, J. Neurophysiol., 43 (1980) 1578-1593.

36 Hall, J.G., Duggan, A.W., Johnson, S.M. and Morton, C.R., Medullary raphe lesions do not reduce descending inhibition of dorsal horn neurones of the cat, Neurosci. Lett., 25 (1981) 25-30.

37 Hall, J.G., Duggan, A.W., Morton, C.R. and Johnson, S.M., The location of brainstem neurones tonically inhibiting dorsal horn neurones of the cat, Brain Research, 244
(1982) 215-222.

38 Halpern, B.P. and Halverson, J.D., Modification of escape from noxious stimuli after bulbar reticular formation lesions, Behav. Biol., 11 (1974) 215-229.

39 Hammond, D.L., Control systems for nociceptive afferent processing: the descending inhibitory pathways. In T.L. Yaksh (Ed.), Spinal Afferent Processing, Plenum, New York, 1986, pp. 363-390.

40 Hammond, G.R., Lesions of the medial medullary reticular area in rats impair CER acquisition, J. Physiol. Psych., 8 (1980) 483-486.

41 Hellon, R.F., and Taylor, D.C.M., An analysis of a thermal afferent pathway in the rat, J. Physiol, (Lond.), 326 (1982) 319-328.

42 Jones, S.L. and Gebhart, G.F., Spinal pathways mediating tonic, coeruleospinal, and raphe-spinal descending inhibition in the rat, J. Neurophysiol., 58 (1987) 138-159.

43 Kelly, S.J. and Franklin, K.B.J., Electrolytic raphe magnus lesions block analgesia induced by a stress-morphine interaction but not analgesia induced by morphine alone, Neurosci Lett., 52 (1984) 147-152.

44 Leblanc, H.J. and Gatipon, G.B., Medial bulboreticular responses to peripherally applied noxious stimuli, Exp. Neurol., 42 (1974) 264-273.

45 Martin, G.F., Vertes, R.P. and Waltzer, R., Spinal projections of the gigantocellular reticular formation in the rat - evidence for projections from different areas to laminae I and II and lamina IX, Exp. Brain Res., 58 (1985) 154-162.

46 Martin, R.F., Jordan, L.M. and Willis, W.D., Differential projections of cat medullary raphe neurons demonstrated by retrograde labelling following spinal cord lesions, $J$. Comp, Neurol., 182 (1978) 77-88.

47 Mohrland, J.S., McManus, D.Q. and Gebhart, G.F., Lesions in nucleus reticularis gigantocellularis: effect on the antinociception produced by microinjection of morphine and focal electrical stimulation in the periaqueductal gray matter, Brain Research, 231 (1982) 143-152.

48 Morrow, T.J. and Casey, K.L., A contact thermal stimulator for neurobehavioral research on temperature sensation, Brain Res. Bull., 6 (1981) 281-284.

49 Morrow, T.J. and Casey, K.L., Suppression of bulboreticular unit responses to noxious stimuli by analgesic mesencephalic stimulation, Somatosens. Res., 1 (1983) 151-168.

50 Nauta, W.J.H. and Kuypers, H.G.J.M., Some ascending pathways in the brain stem reticular formation. In H.H. Jasper and L.D. Proctor (Eds.), Reticular Formation of the Brain, Little, Brown, Boston, 1958, pp. 3-30.

51 Pearl, G.S. and Anderson, K.V., Response patterns of cells in the feline caudal nucleus reticularis gigantocellularis after noxious trigemental and spinal stimulation, Exp. Neurol., 58 (1978) 231-241.

52 Peschanski, M. and Besson, J.-M., Diencephalic connections of the raphe nuclei of the rat brainstem: an anatomical study with reference to the somatosensory system, $J$. Comp. Neurol., 224 (1984) 509-534.

53 Peschanski, M. and Besson, J.-M., A spino-reticulothalamic pathway in the rat: an anatomical study with reference to pain transmission, Neuroscience, 12 (1984) $165-178$.

54 Peterson, B.W., Participation of pontomedullary reticular neurons in specific motor activity. In J.A. Hobson and M.A.B. Brazier (Eds.), The Reticular Formation Revisited, 
Raven, New York, 1980, pp. 171-192.

55 Pretel, S., Guinan, M.J. and Carstens, E., Inhibition of the responses of cat dorsal horn neurons to noxious skin heating by stimulation in medial or lateral medullary reticular formation, Exp. Brain Res., 72 (1988) 51-62.

56 Proudfit, H.K., Reversible inactivation of raphe magnus neurons: effects on nociceptive threshold and morphineinduced analgesia, Brain Research, 201 (1980) 459-464.

57 Proudfit, H.K., Time-course of alterations in morphineinduced analgesia and nociceptive threshold following medullary raphe lesions, Neuroscience, 6 (1981) 945-951.

58 Proudfit, H.K. and Anderson, E.G., Morphine analgesia: blockade by raphe magnus lesions, Brain Research, 98 (1975) 612-618.

59 Saade, N.E., Salibi, N.A., Banna N.R., Towe, A.L. and Jabbur, S.J., Spinal input pathways affecting the medullary gigantocellular reticular nucleus, Exp. Neurol., 80 (1983) $582-600$

60 Sandkuhler, J., Fu, Q.-G. and Zimmerman, M., Spinal pathways mediating tonic or stimulation-produced descending inhibition from the periaqueductal gray or nucleus raphe magnus are separate in the cat, J. Neurophysiol., 58 (1987) 327-341.

61 Sandkuhler, J. and Gebhart, G.F., Characterization of inhibition of a spinal nociceptive reflex by stimulation medially and laterally in the midbrain and medulla in the pentobarbital-anesthetized rat, Brain Research, 305 (1984) 67-76.

62 Sandkuhler, J. and Gebhart, G.F., Relative contributions of the nucleus raphe magnus and adjacent medullary reticular formation to the inhibition by stimulation in the periaqueductal gray of a spinal nociceptive reflex in the pentobarbital-anesthetized rat, Brain Research, 305 (1984) $77-88$.

63 Shimamura, M., Kogure, I. and Wada, S., Three types of reticular neurons involved in the spino-bulbo-spinal reflex of cats, Brain Research, 186 (1980) 99-113.

64 Shimamura, M. and Livingston, R.B., Longitudinal conduction systems serving spinal and brainstem coordination,
J. Neurophysiol., 26 (1963) 258-272.

65 Siegel, J.M., Behavioral functions of the reticular formation, Brain Research, 1 (1979) 69-105.

66 Sjolund, B. and A. Björklund (Eds.), Brain Stem Control of Spinal Mechanisms, Elsevier, Amsterdam. 1983, 523 pp.

67 Taber, E., The cytoarchitecture of the brain stem of the cat. I. Brain stem nuclei of cat, J. Comp. Neurol., 116 (1961) 27-69.

68 Taylor, D.C.M., The effects of nucleus raphe magnus lesions on a ascending thermal pathway in the rat, $J$. Physiol. (Lond.), 326 (1982) 309-318.

69 Vertes, R.P., Martin, G.F. and Waltzer, R., An autoradiographic analysis of ascending projections from the medullary reticular formation in the rat, Neuroscience, 19 (1986) 873-898.

70 Watkins, L.R., Young, E.G., Kinscheck, I.B. and Mayer, D.J., The neural basis of footshock analgesia: the role of specific ventral medullary nuclei, Brain Research, 276 (1983) 305-316.

71 Wolstencroft, J.H., Reticulospinal neurons, J. Physiol. Lond., 174 (1964) 91-108.

72 Wolstencroft, J.H. and West, D.C., Functional characteristics of raphespinal and other projections from nucleus raphe magnus. In B. Sjölund and $A$. Björklund (Eds.), Brain Stem Control of Spinal Mechanisms, Elsevier, Amsterdam, 1982, pp. 359-380.

73 Young, A.A. and Dawson, N.J., Static and dynamic response characteristics, receptive fields, and interaction with noxious input of midline medullary thermoresponsive neurons in the rat, J. Neurophysiol., 57 (1987) 1925-1936.

74 Zemlan, F.P., Kow, L.-M. and Pfaff, D.W., Analgesia after lesions of nucleus reticularis magnocellularis: differential effect on supraspinal versus spinal pain reflexes, Pain, 18 (1984) 221-238.

75 Zemlan, F.P., Behbehani, M.M. and Beckstead, R.M., Ascending and descending projections from nucleus reticularis magnocellularis and nucleus reticularis gigantocellularis: an autoradiographic and horseradish peroxidase study in the rat, Brain Research, 292 (1984) 207-220. 